\title{
Deposition of Gold Nanoparticles via Galvanic Replacement in DMSO and Their Influence on Formation of Silicon Nanostructures
}

\author{
Mariana Shepida $\mathbb{D}^{1},{ }^{1}$ Orest Kuntyi, ${ }^{1}$ Stepan Nichkalo ${ }^{D},{ }^{1}$ Galyna Zozulya, \\ and Sergiy Korniy ${ }^{2}$ \\ ${ }^{1}$ Lviv Polytechnic National University, Lviv 79013, Ukraine \\ ${ }^{2}$ Karpenko Physico-Mechanical Institute of the NAS of Ukraine, Lviv 79060, Ukraine
}

Correspondence should be addressed to Mariana Shepida; maryana_shepida@ukr.net

Received 7 February 2019; Revised 11 April 2019; Accepted 21 April 2019; Published 16 May 2019

Guest Editor: Pradip Basnet

Copyright (C) 2019 Mariana Shepida et al. This is an open access article distributed under the Creative Commons Attribution License, which permits unrestricted use, distribution, and reproduction in any medium, provided the original work is properly cited.

\begin{abstract}
The process of gold nanoparticle (AuNP) precipitation on the silicon ( $\mathrm{Si}$ ) surface by galvanic replacement (GR) in dimethyl sulfoxide (DMSO) solution depending on the concentration of $\mathrm{H}\left[\mathrm{AuCl}_{4}\right]$, temperature, and duration was investigated. It is established that with an increase in the concentration of $\left[\mathrm{AuCl}_{4}\right]^{-}$ions (from 2 to $8 \mathrm{mM} \mathrm{H}\left[\mathrm{AuCl}_{4}\right]$ ), both the size of AuNPs and their surface coverage density are increased. It is demonstrated that an increase in temperature causes the size of AuNPs to increase from 40 to $80 \mathrm{~nm}$ at $40^{\circ} \mathrm{C}$ to $80-120$ and $120-160 \mathrm{~nm}$ at 50 and $60^{\circ} \mathrm{C}$, respectively. As the duration of the GR process increases, there is a tendency of the particle size growth. Under the studied deposition conditions, the organic aprotic solvent medium contributes to the formation of spherical AuNPs with 2D substrate filling. It is established that the AuNPs deposited on the silicon surface catalyze the process of metal-assisted chemical etching (MacEtch), which makes it possible to obtain Si nanostructures in the form of nanowire arrays.
\end{abstract}

\section{Introduction}

MacEtch is one of the anisotropic methods for obtaining Si nanostructures of different morphologies, in particular porous $\mathrm{Si}[1-4]$, nanowires, and complex nanostructures [5-10]. They are the basis for modern devices used in nanoelectronics [11], optoelectronics [12-15], and devices for energy conversion and storage [16-19]. This method involves the deposition of the discrete metal nanoparticles as well as the porous metal nanofilms on the Si surface. These metals serve as the catalysts of local etching of the substrate in solutions based on oxidant and acid [1]. MacEtch occurs through the electrochemical mechanism, when metal nanoparticles (MNPs) are the cathode regions and the silicon surface in direct contact with MNPs is the anode. Thus, electrochemical reduction of hydrogen in the cathode region and local dissolution of $\mathrm{Si}$ with the formation of pores in the anode region occur. The higher potential difference
$\left(\Delta E=E_{\mathrm{M}^{n+} / \mathrm{M}}^{0}-E_{\mathrm{Si}^{++} / \mathrm{Si}}^{0}\right)$ between cathode and anode sections leads to the greater rate of these processes. This is primarily due to the value of the standard electrode potential for the metal $\left(E_{\mathrm{M}^{n+} / \mathrm{M}}^{0}\right)$. Therefore, metals which are characterized by high values of this parameter, such as noble metals $(\mathrm{Au}, \mathrm{Pt}$, $\mathrm{Ag}$, and Pd), are used for MacEtch [8, 14, 19-21]. Noble metals are also characterized by high chemical and electrochemical resistance at the nanoscale level. The predominant use of AuNPs as the catalysts in the MacEtch method is due to the highest value of its standard electrode potential $\left(E_{\mathrm{Au}^{3+} / \mathrm{Au}}^{0}=1.49 \mathrm{~V}\right)$ and, consequently, to its high catalytic activity. This contributes to directional local vertical etching of the Si surface and allows the Si nanowires to be extracted with a high aspect ratio $[1,5,10]$.

The most common methods of metal nanoparticle (MNP) deposition on a Si surface are the physical ones $[22,23]$. They require the use of expensive equipment and are energy consuming. Therefore, in the last decade, there is 
a tendency to find alternative methods, among which is GR [24-26]. Mostly, GR is carried out in an aqueous solution, where the hydrogen release on cathode regions and the etching of a substrate occur besides the main process of metal recovery as byprocesses [25, 27-30]. This complicates the controlled formation of MNPs, as a necessary condition for the surface modification. As it was shown in our previous works [31-34], GR in the organic solvent medium overcomes these disadvantages of aqueous solutions. In addition, organic solvents often play a role of a surfactant due to their electron-donor properties, affecting the geometry of nanoparticles and their size distribution.

This study aims to establish the optimal conditions for the control over the deposition process of catalytically active AuNPs with good density and geometry on the Si substrate surface by GR method thanks to the use of DMSO solvent. These synthesized AuNPs are predicted to be used for fabrication of Si nanostructures of given morphology via the MacEtch method.

\section{Experimental}

For our studies, $\mathrm{n}-\mathrm{Si}(100)$ substrates with resistivity of $4 \Omega \cdot \mathrm{cm}$ were used. The substrate was cut into equal pieces of $1 \times 1 \mathrm{~cm}^{2}$. The samples were preliminary washed in acetone and ethanol in ultrasonic bath and then etched in a solution containing 5\% HF and DMSO solvent for $10 \mathrm{~min}$. The deposition of gold on a $\mathrm{Si}$ surface was carried out by the GR method from solutions of 2-8 $\mathrm{mM} \mathrm{HAuCl}_{4}\left(\mathrm{HAuCl}_{4} \cdot 3 \mathrm{H}_{2} \mathrm{O}\right.$, $99.99 \%$, Alfa Aesar) in the presence of HF (1\% mass) in DMSO solvent (99\%, Alfa Aesar). Afterwards, the samples were immersed in a solution of metal salt and kept in a hydrostatic mode at the temperatures of $40-60^{\circ} \mathrm{C}$ for $0.5-$ 4 min. After AuNPs were deposited onto Si surface, the samples were washed sequentially with ethanol and acetone and dried at the temperature of $60^{\circ} \mathrm{C}$.

The etching of the modified Si surface was carried out in a solution based on $\mathrm{HF}(40 \%), \mathrm{H}_{2} \mathrm{O}_{2}(35 \%)$, and deionized water $\mathrm{H}_{2} \mathrm{O}$. The volumetric ratio of the components used in etching solution was $4: 1: 4$. The etching was performed for a duration of $15 \mathrm{~min}$ at room temperature, after which the samples were washed in deionized water and dried in a heat chamber $\left(80^{\circ} \mathrm{C}\right)$.

The morphology of the Si surface after the AuNP deposition and MacEtch was studied using scanning electron microscopes ZEISS EVO 40XVP and SELMI REM-106I, respectively. The images of the modified surface were obtained by recording secondary electrons by scanning an electron beam of $20 \mathrm{kV}$ energy. The chemical composition of the resulting precipitates was characterized using the energydispersive X-ray spectroscopy (EDX).

AuNP size and density were determined by using the public domain Java image processing program ImageJ2 [35]. The ImageJ2 package is a free cross-platform software with an open architecture that allows calculating areas and statistical indicators of pixel values of different areas on images, extracted manually or using threshold functions. The statistical histograms were obtained using ORIGIN software pack with its standard deviation values of nanoparticle size.

\section{Results and Discussion}

Galvanic replacement of gold by silicon in DMSO-based $\mathrm{H}$ $\left[\mathrm{AuCl}_{4}\right]$ solutions containing HF occurs by reaction (1). The process is carried out according to the electrochemical mechanism, which includes the presence of anode and cathode regions on the substrate surface where the electrically generating half-reaction (2) and the half-reaction of the $\left[\mathrm{AuCl}_{4}\right]^{-}$ion reduction (3) are localized. The high value of the electromotive force of the process $\Delta \mathrm{E}^{0}\left(E_{\mathrm{Au}^{3+} / \mathrm{Au}}^{0}-E_{\left[\mathrm{SiF}_{6}\right]^{2-} / \mathrm{Si}}^{0}=2.62 \mathrm{~V}\right)$ provides high cathode current densities and, accordingly, high rates of total reaction (1).

$$
4\left[\mathrm{AuCl}_{4}\right]^{-}+3 \mathrm{Si}+18 \mathrm{~F}^{-}=4 \mathrm{Au}+16 \mathrm{Cl}^{-}+3\left[\mathrm{SiF}_{6}\right]^{2-}
$$

$$
\begin{aligned}
& \text { Anode region: } \mathrm{Si}+6 \mathrm{~F}^{-} \longrightarrow\left[\mathrm{SiF}_{6}\right]^{2-}+4 \mathrm{e} \text {, } \\
& E_{0}=-1.20 \mathrm{~V}
\end{aligned}
$$

$$
\begin{aligned}
& \text { Cathode region: }\left[\mathrm{AuCl}_{4}\right]^{-}+3 \mathrm{e} \longrightarrow \mathrm{Au}+4 \mathrm{Cl}^{-} \text {, } \\
& E_{0}=1.42 \mathrm{~V}
\end{aligned}
$$

The high stability of complex ions $\left[\mathrm{AuCl}_{4}\right]^{-}\left(K_{\text {instab. }}\right.$ $=1 \cdot 10^{-19}$ ) causes a significant cathode polarization of gold reduction. Cathodic polarization also intensifies the formation of surface complexes on nanoclusters and metal nanoparticles due to donor-acceptor coupling of adsorbed donor-based solvent molecules [31]. This contributes to the formation of small-sized spherical particles, as well as their uniform distribution over the whole substrate surface (Figures (1)-(3)). As it follows from EDX analysis, GR in DMSO solvent results in the formation of Au deposits on the surface of $\mathrm{Si}$ (Figure 1(d)).

The concentration of precipitating metal ions and the temperature significantly affect the cathodic polarization. Thus, with an increase in the concentration of $\mathrm{H}\left[\mathrm{AuCl}_{4}\right]$ from 2 to $8 \mathrm{mM}$, the particles' size and their density on the $\mathrm{Si}$ surface increase (Figure 1). A tendency of the agglomerates formation is also observed (Figure 1(c)). However, there is a 2D substrate filling with particles up to $100 \mathrm{~nm}$ in size (Figures 1(a) and 1(b)). Consequently, the concentration of ions $\left[\mathrm{AuCl}_{4}\right]^{-}$is an effective factor of influence on the morphology of AuNPs deposited by GR onto the Si surface.

The temperature in the electrochemical processes is a depolarizing factor. When it increases, the rate of the electrically generating reaction of the anode dissolution of $\mathrm{Si}$ rises (2) and, consequently, the current density at the cathode regions $\left(i_{\text {cathode }}\right)$ increases, thus leading to an intensification of the cathode metal reduction (3). Therefore, an increase in the temperature from 40 to $60^{\circ} \mathrm{C}$ tends to cover the substrate surface by the increasing amount of deposited AuNPs (Figures 1(b), 2(a), and 2(b)). An increase in the temperature also causes desorption of DMSO molecules from nanoclusters and AuNPs. Consequently, the inhibitory effect of the surface complexes on the nanoparticle growth decreases, and the "smoothing" effect is neglected. Therefore, the size of AuNPs increases from 40 to $80 \mathrm{~nm}$ at $40^{\circ} \mathrm{C}$ to $80-120 \mathrm{~nm}$ and $120-160 \mathrm{~nm}$ at 50 and $60^{\circ} \mathrm{C}$, respectively (Figures $2(\mathrm{c})$ and $2(\mathrm{~d})$ ). 


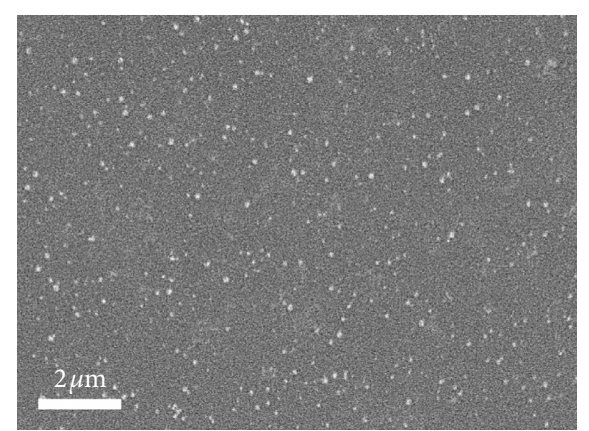

(a)

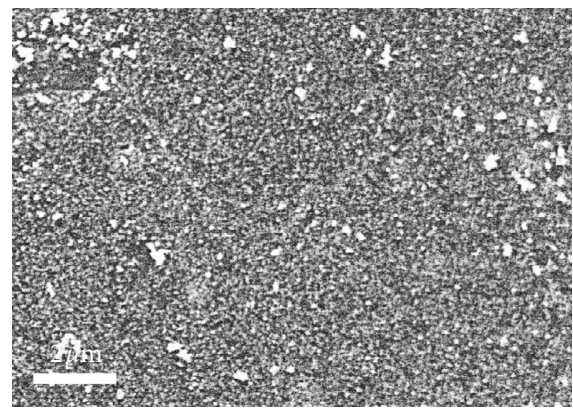

(c)

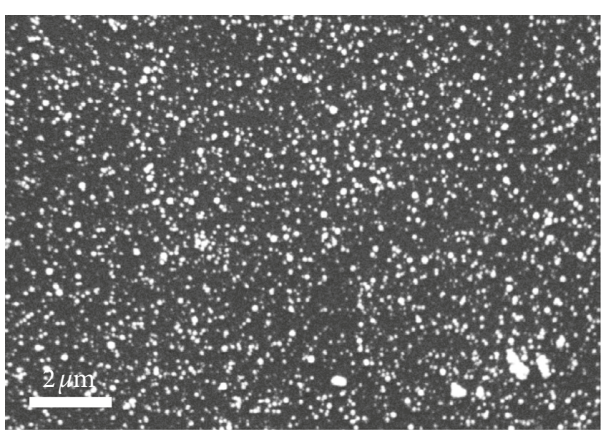

(b)

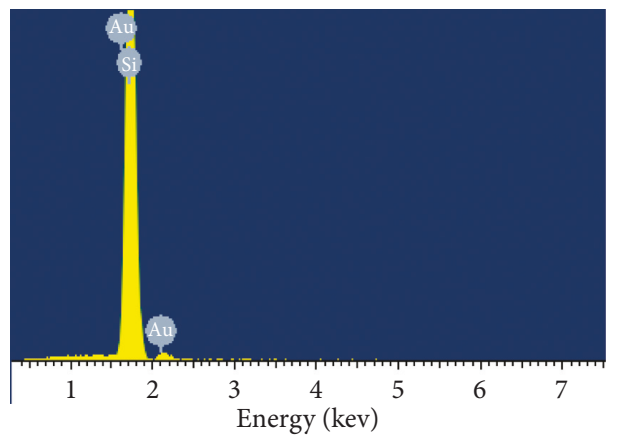

(d)

FIGURE 1: SEM image of the Si surface covered with gold deposited from a solution containing $2 \mathrm{mM}$ (a), $4 \mathrm{mM}(\mathrm{b})$, and $8 \mathrm{mM}$ (c) $\mathrm{H}[\mathrm{AuCl}$ ] by the GR method in the DMSO solvent for $1 \mathrm{~min}$ at $50^{\circ} \mathrm{C}$ and EDX spectrum (d).

During GR of gold on the Si surface by reaction (1), the size of AuNPs grows in time without an increase in their amount (Figure 3(d)). This indicates that the process of nucleation occurs in the initial period of GR, and in the future, the predominant growth of the formed particles takes place (Figures 3(a)-3(c)). It is known [36] that the activation energy of the nucleation process is much greater than that of the nanocluster and nanoparticle growth. Therefore, the last process has a priority. Thus, the duration of GR process is one of the factors influencing the sizes of AuNPs on the $\mathrm{Si}$ surface.

One of the main applications of galvanic replacement of AuNPs on the surface of $S i$ is the creation of Si nanowires. At the same time, it is important to obtain an array of discrete $\mathrm{Au}$ nanoparticles. Wu et al. [2] synthesized dendritic Au layers on the Si wafer surface by the GR method. Furthermore, they have shown that the MacEtch of such samples produces a porous structure but not an array of nanowires. In contrast to the authors of the paper [2], we synthesized discrete AuNPs by the GR method, the compactness and density of which on the Si wafer surface being controlled by selecting a proper temperature and deposition time. No dendritic structures were found, however.

Next, we used these synthesized AuNPs for fabrication of Si nanowires of given morphology by means of the MacEtch method. As a result of etching of the Si wafer samples covered with AuNPs deposited from a solution of $4 \mathrm{mM} \mathrm{H}$ $\left[\mathrm{AuCl}_{4}\right]$ at $50^{\circ} \mathrm{C}$ in the $\mathrm{HF}-\mathrm{H}_{2} \mathrm{O}_{2}-\mathrm{H}_{2} \mathrm{O}$ etchant for $15 \mathrm{~min}$, the arrays of $\mathrm{Si}$ nanowires on a $\mathrm{Si}$ wafer surface were formed (Figure 4). The morphology of Si nanowires is similar to those obtained by other scientists [37]. Such a rough surface morphology is promising from the point of view of ultrahigh light absorption, where the nanoforest acts as an antireflective surface.

In Figure 4(a) we see that the nanowires are quite densely spaced, forming a thick nanoforest. So, in this case, it makes sense to conclude a high surface coverage of $\mathrm{Si}$ wafer with nanowires.

The cross section SEM image (Figure 4(b)) allows to estimate the main nanorod parameters and average size. The nanowires' diameter ranges from 100 to $300 \mathrm{~nm}$, and the height is about $2.5 \mu \mathrm{m}$ (estimated from inset in Figure 4(b)). The vertical etching rate was $167 \mathrm{~nm} / \mathrm{min}$, so the height is a function of etching time. We can predict that with longer etching times the height of the nanoforest will increase. As the nanowires' height was the same order, we can assume that the AuNPs synthesized in the DMSO solvent show a good adhesion to the surface of $\mathrm{Si}$ wafer. Further studies are needed however.

All technological conditions for the AuNP formation on the surface of silicon wafers are suitable for the nanowire fabrication, since, as it was shown in $[9,37], \mathrm{Si}$ nanostructures are formed using the metal catalysts both, in the form of discrete close-packed particles, and porous films as well. On the other hand, AuNPs in the form of a porous film are not suitable for plasmonics as the plasmon effects depend on the size and distance between the metal nanoparticles. In our case, the technological conditions for the deposition of AuNPs allow to obtain discrete particles in which plasmon effects can be manifested. These issues require further studies. 


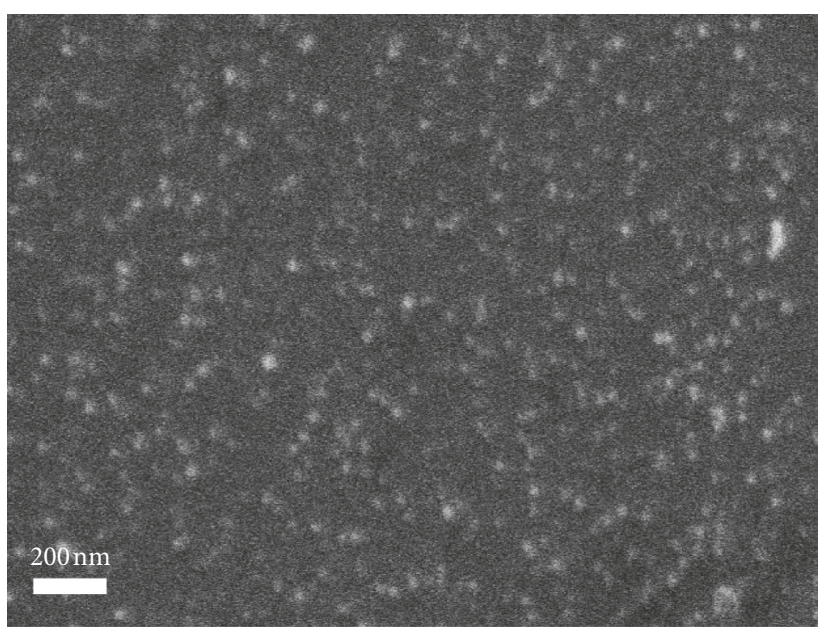

(a)

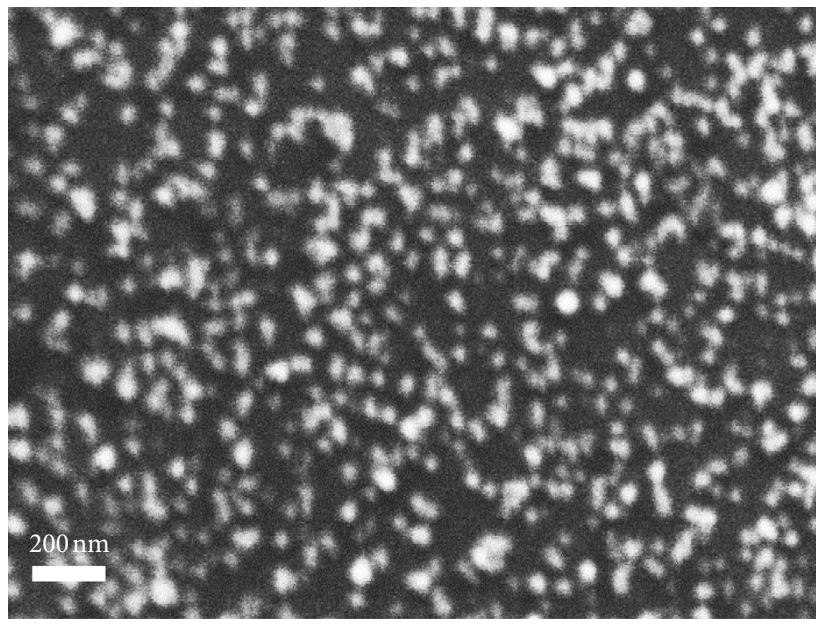

(c)

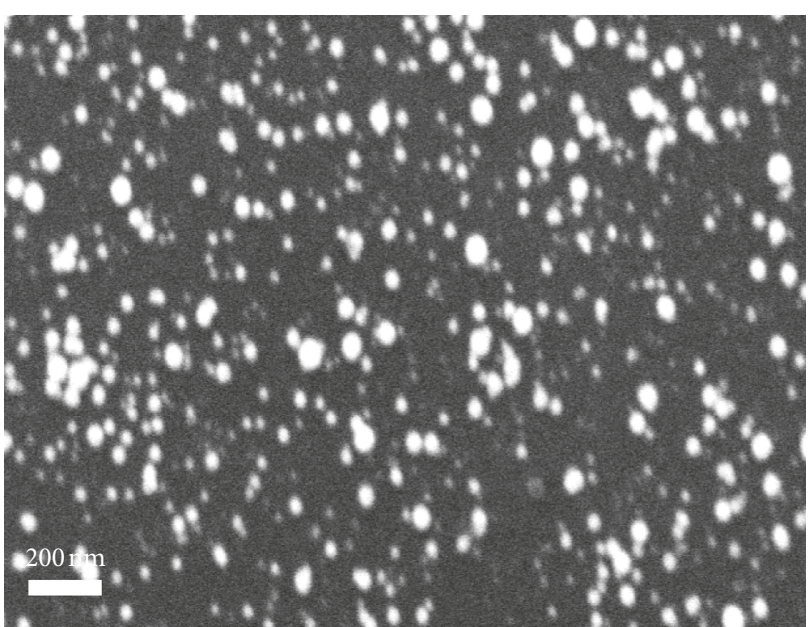

(b)

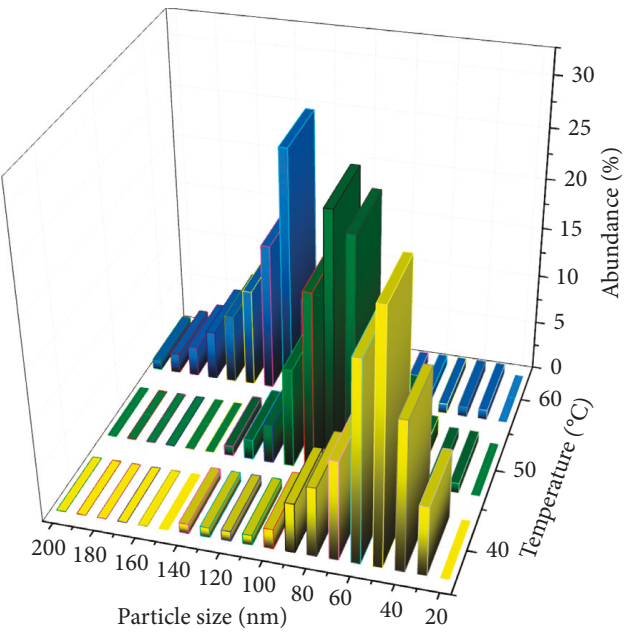

(d)

FIGURE 2: SEM image of the Si surface covered with gold deposited from a solution of $4 \mathrm{mM} \mathrm{H}\left[\mathrm{AuCl}_{4}\right]$ by the GR method in DMSO for 1 min at $40^{\circ} \mathrm{C}(\mathrm{a}), 50^{\circ} \mathrm{C}(\mathrm{b})$, and $60^{\circ} \mathrm{C}(\mathrm{c})$, and the size distribution histograms of AuNPs (d).

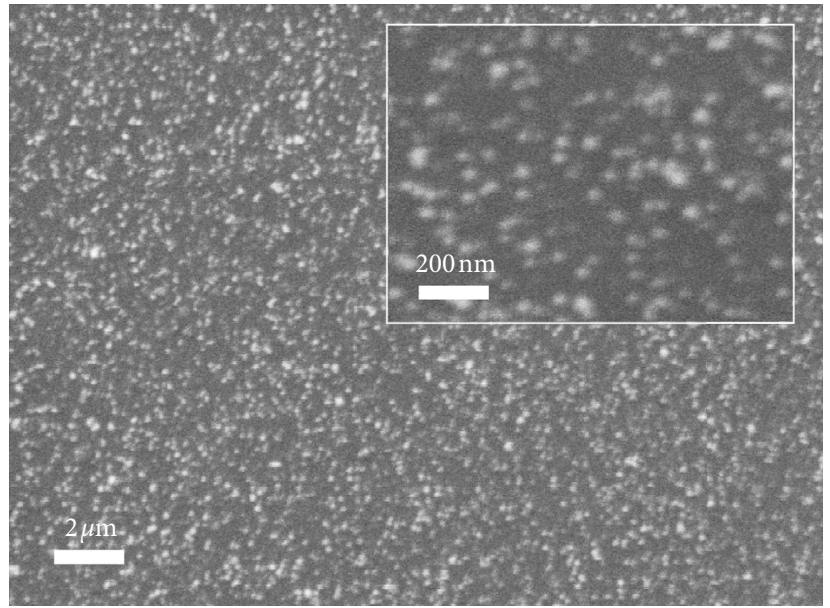

(a)

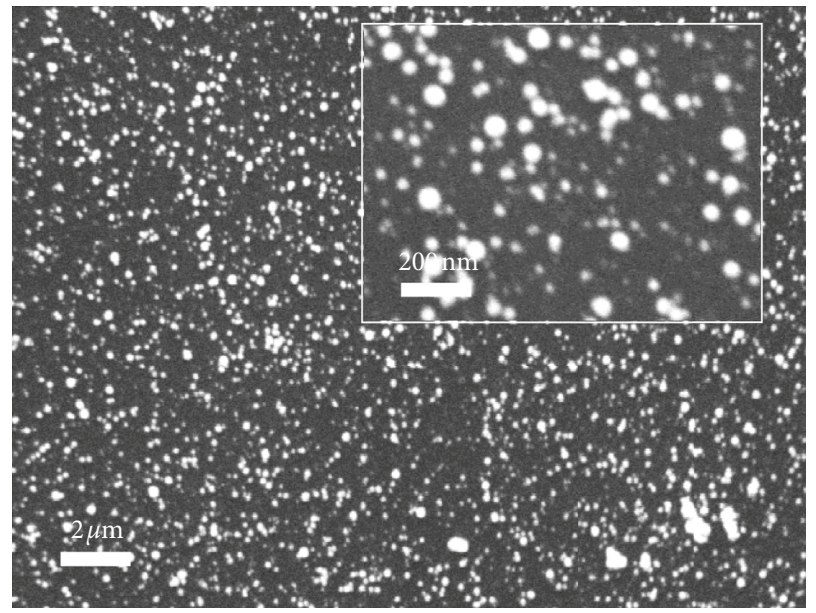

(b)

Figure 3: Continued. 


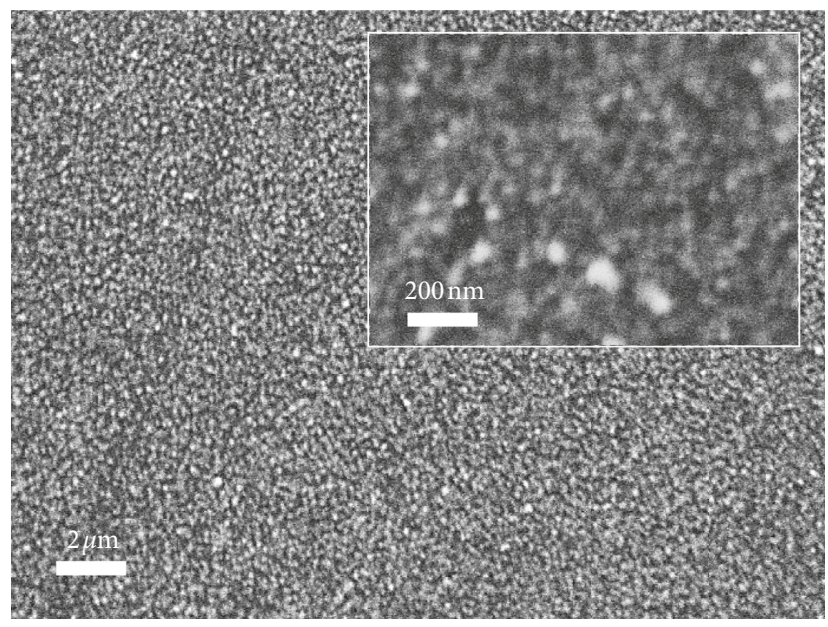

(c)

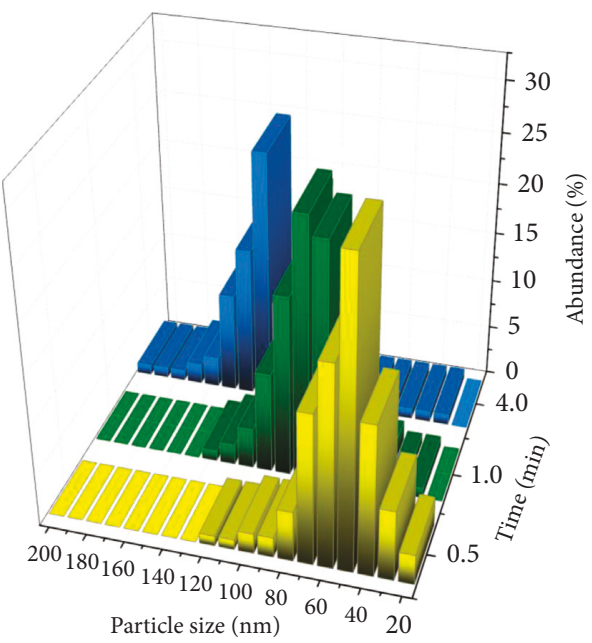

(d)

FIGURE 3: SEM image of the Si surface covered with gold deposited from a solution of $4 \mathrm{mM} \mathrm{H}\left[\mathrm{AuCl}_{4}\right]$ by the GR method in DMSO at $50^{\circ} \mathrm{C}$ for $0.5 \mathrm{~min}(\mathrm{a}), 1 \mathrm{~min}(\mathrm{~b})$, and $4 \mathrm{~min}$ (c), and the size distribution histograms of AuNPs (d).

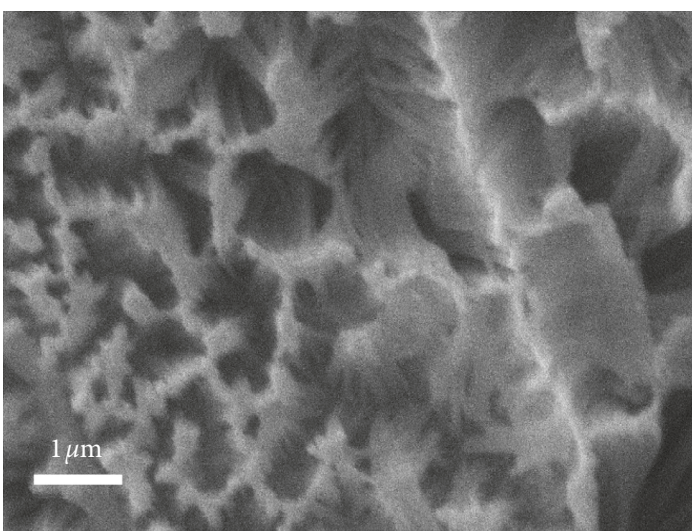

(a)

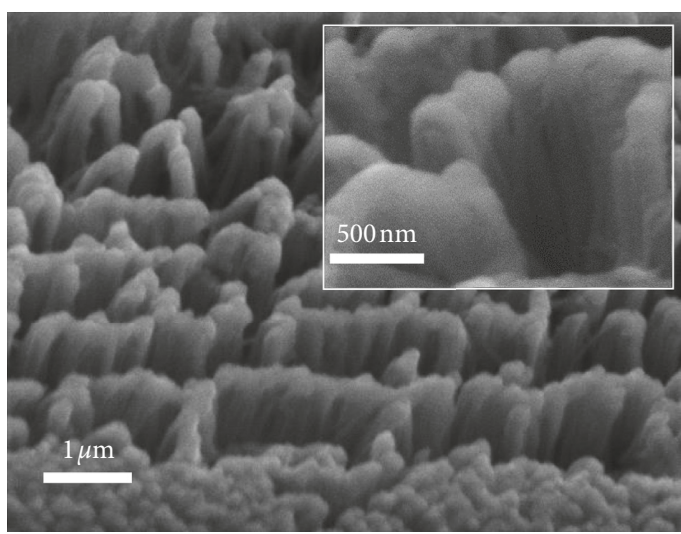

(b)

Figure 4: Top-view (a) and cross section (b) SEM images of Si nanowires arrays formed after the 15 min $\mathrm{HF}_{-}-\mathrm{H}_{2} \mathrm{O}_{2}-\mathrm{H}_{2} \mathrm{O}$ etching of Si substrate covered with AuNPs deposited from a solution of $4 \mathrm{mM} \mathrm{H}\left[\mathrm{AuCl}_{4}\right]$ at $50^{\circ} \mathrm{C}$.

\section{Conclusions}

Gold nanoparticles up to $100 \mathrm{~nm}$ are deposited on the Si surface at $2-8 \mathrm{mM} \mathrm{H}\left[\mathrm{AuCl}_{4}\right]$ in the DMSO solvent in the presence of fluoride ions by the GR method at $40-60^{\circ} \mathrm{C}$. The organic aprotic solvent medium contributes to the formation of spherical metal particles and the $2 \mathrm{D}$ surface filling of the Si surface and also prevents the side processes to occur during GR. The main factors influencing the size of AuNPs are the concentration of $\mathrm{H}\left[\mathrm{AuCl}_{4}\right]$, temperature, and the process duration. As their values increase, the size of the nanoparticles increases as well. Gold nanoparticles synthesized by the GR method in the mixture of $\mathrm{H}\left[\mathrm{AuCl}_{4}\right]$ and organic DMSO solvent on the Si wafer surface gave the possibility to produce more complex structures by means of the MacEtch technique in the form of Si nanowire arrays, which are one of the most promising materials for modern nanoelectronic devices. Thus, the control over the process of
GR of AuNPs of given morphology, shape, size, and distribution on the Si surface opens up the opportunity to create more complex device structures.

\section{Data Availability}

The data used to support the findings of this study are included within the article.

\section{Conflicts of Interest}

The authors declare that there are no conflicts of interest regarding the publication of this paper.

\section{Acknowledgments}

This work was financially supported by the Ministry of Education and Science of Ukraine under the project 
"Controlled electrochemical synthesis of metal nanoparticles and nanostructured materials" (State Registration no. 0118U000268).

\section{References}

[1] Z. Huang, N. Geyer, P. Werner, J. de Boor, and U. Gösele, "Metal-assisted chemical etching of silicon: a review," Advanced Materials, vol. 23, no. 2, pp. 285-308, 2011.

[2] H.-L. Wu, C.-H. Chen, and M. H. Huang, "Seed-mediated synthesis of branched gold nanocrystals derived from the side growth of pentagonal bipyramids and the formation of gold nanostars," Chemistry of Materials, vol. 21, no. 1, pp. 110-114, 2009.

[3] A. Druzhinin, V. Yerokhov, S. Nichkalo, and Y. Berezhanskyi, "Micro- and nanotextured silicon for antireflective coatings of solar cells," Journal of Nano Research, vol. 39, pp. 89-95, 2016.

[4] R. F. Balderas-Valadez, V. Agarwal, and C. Pacholski, "Fabrication of porous silicon-based optical sensors using metal-assisted chemical etching," RSC Advances, vol. 6, no. 26, pp. 21430-21434, 2016.

[5] J. M. Duran and A. Sarangan, "Fabrication of ultrahigh aspect ratio silicon nanostructures using selfassembled gold metalassisted chemical etching," Journal of Micro/Nanolithography, MEMS, and MOEMS, vol. 16, no. 1, article 014502, 2017.

[6] A. Stafiniak, J. Prażmowska, W. Macherzyński, and R. Paszkiewicz, "Nanostructuring of Si substrates by a metalassisted chemical etching and dewetting process," RSC Advances, vol. 8, no. 54, pp. 31224-31230, 2018.

[7] S. Ashrafabadi and H. Eshghi, "Single-crystalline Si nanowires fabrication by one-step metal assisted chemical etching: the effect of etching time and resistivity of Si wafer," Superlattices and Microstructures, vol. 120, pp. 517-524, 2018.

[8] P. V. Trinh, P. N. Hong, B. H. Thang et al., "Effect of surface morphology and dispersion media on the properties of PEDOT:PSS/n-Si hybrid solar cell containing functionalized graphene," Advances in Materials Science and Engineering, vol. 2017, Article ID 2362056, 9 pages, 2017.

[9] S. Nichkalo, A. Druzhinin, A. Evtukh, O. Bratus', and O. Steblova, "Silicon nanostructures produced by modified MacEtch method for antireflective Si surface," Nanoscale Research Letters, vol. 12, no. 1, p. 106, 2017.

[10] B. Miao, J. Zhang, X. Ding et al., "Improved metal assisted chemical etching method for uniform, vertical and deep silicon structure," Journal of Micromechanics and Microengineering, vol. 27, no. 5, article 055019, 2017.

[11] H. Han, Z. Huang, and W. Lee, "Metal-assisted chemical etching of silicon and nanotechnology applications," Nano Today, vol. 9, no. 3, pp. 271-304, 2014.

[12] R. F. Balderas-Valadez, J. O. Estévez-Espinoza, U. SalazarKuri, C. Pacholski, W. L. Mochan, and V. Agarwal, "Fabrication of ordered tubular porous silicon structures by colloidal lithography and metal assisted chemical etching: SERS performance of 2D porous silicon structures," Applied Surface Science, vol. 462, pp. 783-790, 2018.

[13] A. A. Druzhinin, Lviv Polytechnic National University, S. I. Nichkalo, and O. Y. Ostapiv, "Development of antireflecting surfaces based on $\mathrm{Si}$ micropyramids and wetchemically etched Si nanowire arrays," Functional Materials, vol. 25, no. 4, pp. 675-680, 2018.

[14] M. Lajvardi, H. Eshghi, M. Izadifard, M. E. Ghazi, and A. Goodarzi, "Effects of silver and gold catalytic activities on the structural and optical properties of silicon nanowires,"
Physica E: Low-Dimensional Systems and Nanostructures, vol. 75, pp. 136-143, 2016.

[15] M. Pavlenko, E. L. Coy, M. Jancelewicz et al., "Enhancement of optical and mechanical properties of Si nanopillars by ALD TiO2 coating," RSC Advances, vol. 6, no. 99, pp. 97070-97076, 2016.

[16] S. Nichkalo, A. Druzhinin, V. Yerokhov, and O. Ostapiv, "Fabrication and characterization of high-performance antireflecting nanotextured Si surfaces for solar cells," Nanooptics, Nanophotonics, Nanostructures, and Their Applications, vol. 210, pp. 275-283, 2018.

[17] W. McSweeney, H. Geaney, and C. O’Dwyer, "Metal-assisted chemical etching of silicon and the behavior of nanoscale silicon materials as Li-ion battery anodes," Nano Research, vol. 8, no. 5, pp. 1395-1442, 2015.

[18] K.-Q. Peng and S.-T. Lee, "Silicon nanowires for photovoltaic solar energy conversion," Advanced Materials, vol. 23, no. 2, pp. 198-215, 2011.

[19] M.-H. Shiao, C.-P. Lai, B.-H. Liao, and Y.-S. Lin, "Effect of photoillumination on gold-nanoparticle-assisted chemical etching of silicon," Journal of Nanomaterials, vol. 2018, Article ID 5479605, 5 pages, 2018.

[20] N. Geyer, B. Fuhrmann, Z. Huang, J. de Boor, H. S. Leipner, and P. Werner, "Model for the mass transport during metalassisted chemical etching with contiguous metal films as catalysts," The Journal of Physical Chemistry C, vol. 116, no. 24, pp. 13446-13451, 2012.

[21] J.-M. Chen, C.-Y. Chen, C. P. Wong, and C.-Y. Chen, "Inherent formation of porous p-type $\mathrm{Si}$ nanowires using palladium-assisted chemical etching," Applied Surface Science, vol. 392, pp. 498-502, 2017.

[22] C. Zhang, K. Lin, Y. Huang, and J. Zhang, "Graphene-Ag hybrids on laser-textured Si surface for SERS detection," Sensors, vol. 17, no. 7, pp. 1462-1470, 2017.

[23] Z. Huang, X. Zhang, M. Reiche et al., "Extended arrays of vertically aligned sub-10 $\mathrm{nm}$ diameter [100] Si nanowires by metal-assisted chemical etching," Nano Letters, vol. 8, no. 9, pp. 3046-3051, 2008.

[24] Q. Wei, Y.-S. Shi, K.-Q. Sun, and B.-Q. Xu, "Pd-on-Si catalysts prepared via galvanic displacement for the selective hydrogenation of para-chloronitrobenzene," Chemical Communications, vol. 52, no. 14, pp. 3026-3029, 2016.

[25] S. S. Djokić and K. Cadien, "Galvanic deposition of silver on silicon surfaces from fluoride free aqueous solutions," ECS Electrochemistry Letters, vol. 4, no. 6, pp. 11-13, 2015.

[26] A. Raygani and L. Magagnin, "Gold metallization of silicon by galvanic displacement," Electrochemical Society (ECS) Transactions, vol. 41, pp. 3-8, 2012.

[27] A. Gutes, I. Laboriante, C. Carraro, and R. Maboudian, "Palladium nanostructures from galvanic displacement as hydrogen peroxide sensor," Sensors and Actuators B: Chemical, vol. 147, no. 2, pp. 681-686, 2010.

[28] C. Carraro, R. Maboudian, and L. Magagnin, "Metallization and nanostructuring of semiconductor surfaces by galvanic displacement processes," Surface Science Reports, vol. 62, no. 12, pp. 499-525, 2007.

[29] A. Gutés, C. Carraro, and R. Maboudian, "Ultrasmooth gold thin films by self-limiting galvanic displacement on silicon," ACS Applied Materials \& Interfaces, vol. 3, no. 5, pp. 15811584, 2011.

[30] S. Y. Sayed, F. Wang, M. Malac, A. Meldrum, R. F. Egerton, and J. M. Buriak, "Heteroepitaxial growth of gold nanostructures on silicon by galvanic displacement," ACS Nano, vol. 3, no. 9, pp. 2809-2817, 2009. 
[31] O. Kuntyi, Lviv Polytechnic National University, M. Shepida et al., "Modification of silicon surface with silver, gold and palladium nanostructures via galvanic substitution in DMSO and DMF solutions," Chemistry \& Chemical Technology, vol. 12, no. 3, pp. 305-309, 2018.

[32] H. Itasaka, M. Nishi, M. Shimizu, and K. Hirao, "Growth of nanogold at interfaces between locally induced naked silicon surfaces and pure $\mathrm{HAuCl}_{4}$ solutions," Journal of The Electrochemical Society, vol. 163, no. 14, pp. D743-D746, 2016.

[33] O. Y. Dobrovets'ka, O. I. Kuntyi, G. I. Zozulya, I. V. Saldan, and O. V. Reshetnyak, "Galvanic deposition of gold and palladium on magnesium by the method of substitution," Materials Science, vol. 51, no. 3, pp. 418-423, 2015.

[34] Y.-C. Wang, J.-Y. Lin, C.-H. Wang, P.-L. Huang, S.-L. Lee, and J.-K. Chang, "Formation of metal coatings on magnesium using a galvanic replacement reaction in ionic liquid," RSC Advances, vol. 4, no. 67, p. 35298, 2014.

[35] C. T. Rueden, J. Schindelin, M. C. Hiner et al., "ImageJ2: imageJ for the next generation of scientific image data," $B M C$ Bioinformatics, vol. 18, no. 1, p. 529, 2017.

[36] S. Simeonova, P. Georgiev, K. S. Exner et al., "Kinetic study of gold nanoparticles synthesized in the presence of chitosan and citric acid," Colloids and Surfaces A: Physicochemical and Engineering Aspects, vol. 557, pp. 106-115, 2018.

[37] M.-L. Seol, J.-H. Ahn, J.-M. Choi, S.-J. Choi, and Y.-K. Choi, "Self-aligned nanoforest in silicon nanowire for sensitive conductance modulation," Nano Letters, vol. 12, no. 11, pp. 5603-5608, 2012. 


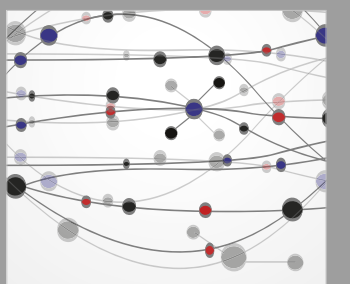

The Scientific World Journal
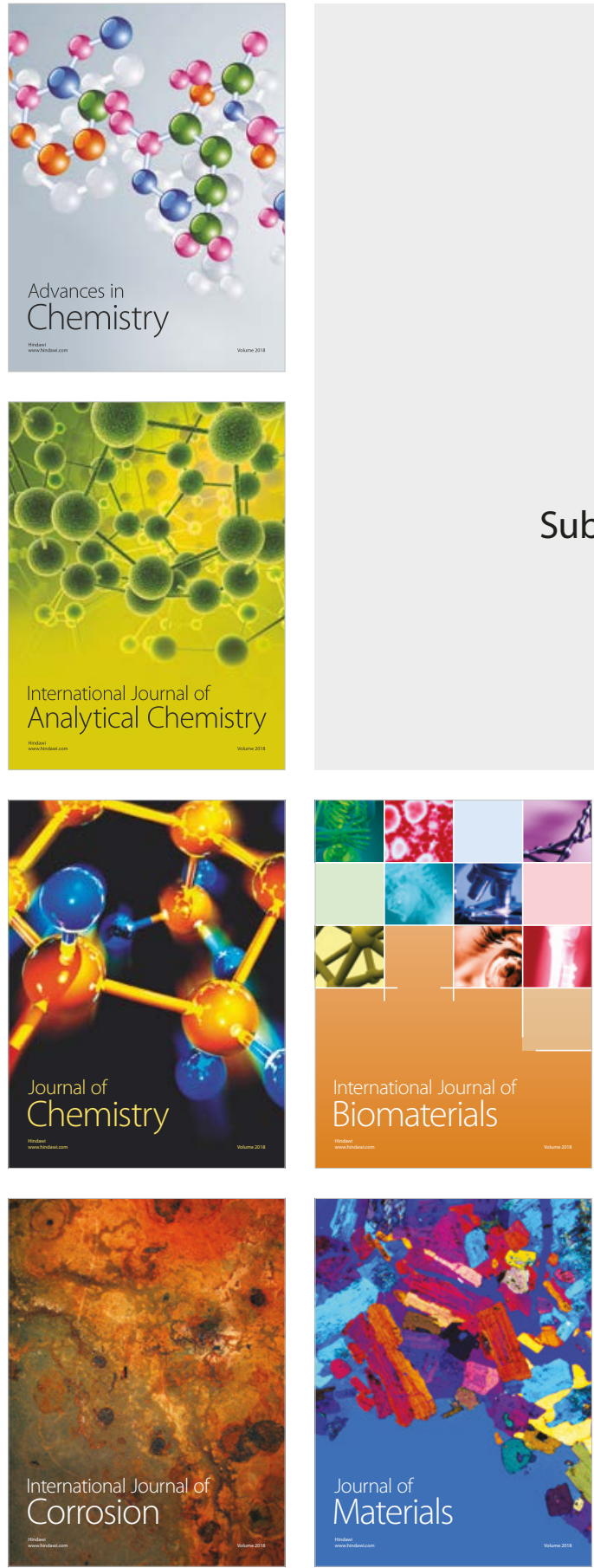

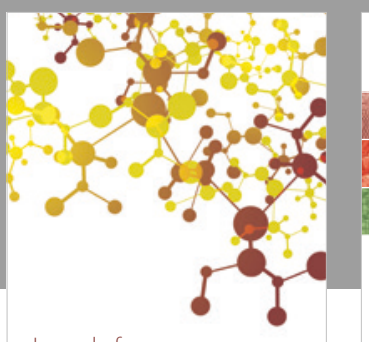

Journal of

Applied Chemistry
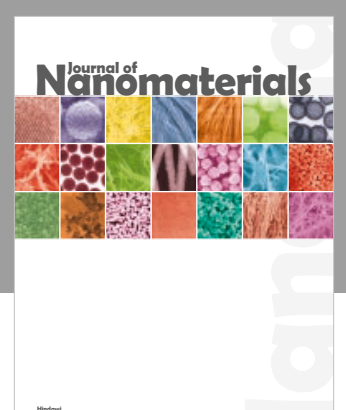

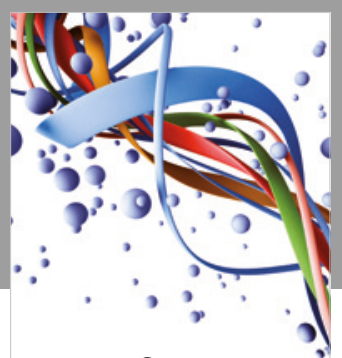

Scientifica

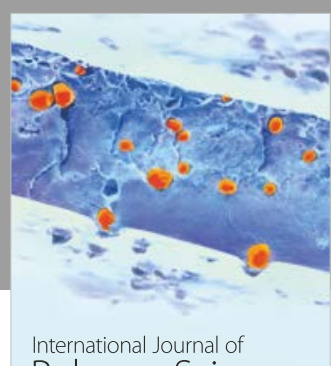

Polymer Science

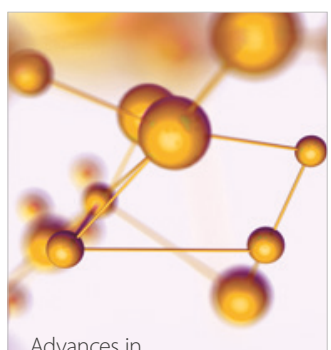

Physical Chemistry
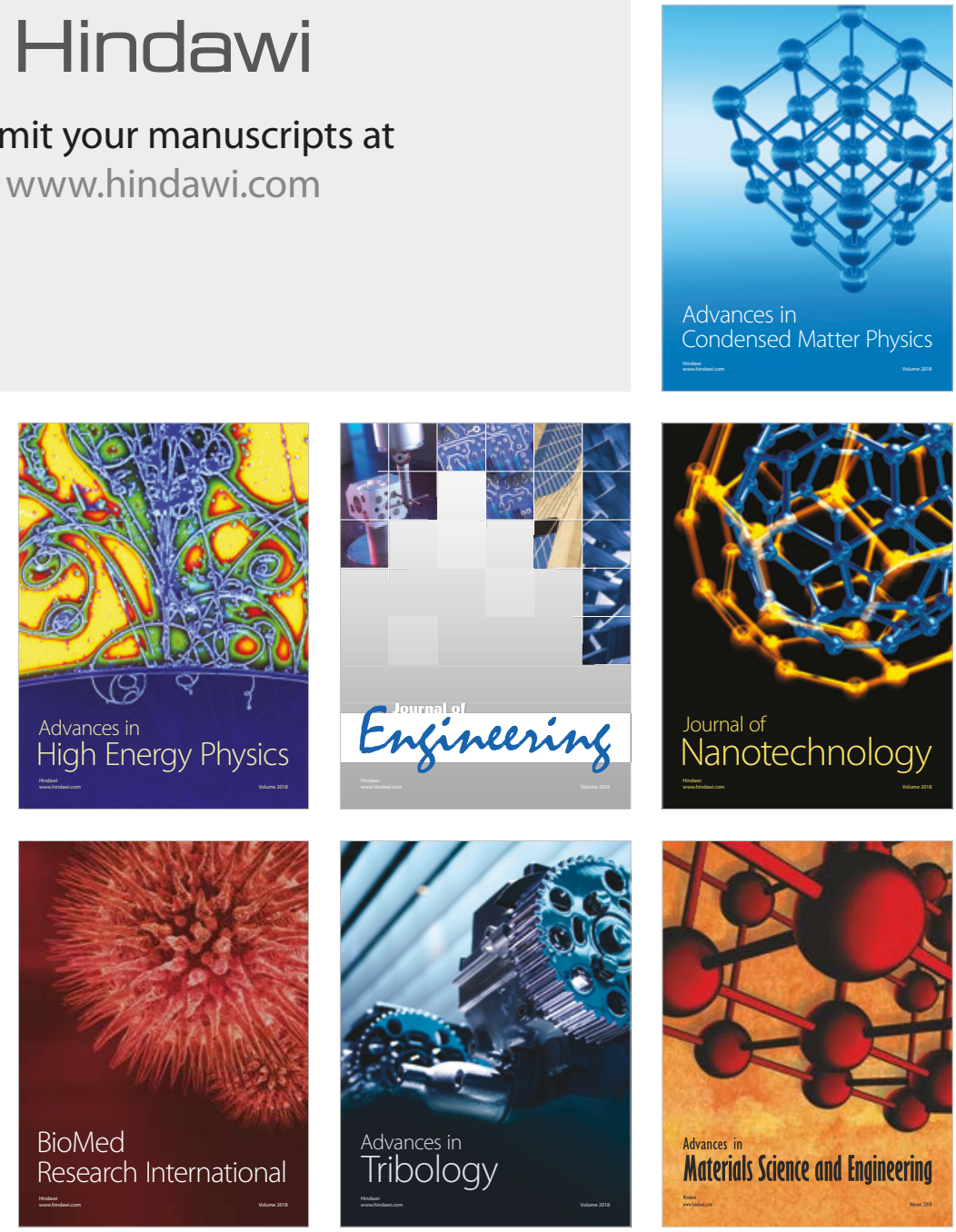